\title{
RADIO FREQUENCY EMF EXPOSURE DUE TO GSM MOBILE PHONES BASE STATIONS: MEASUREMENTS AND ANALYSIS IN NIGERIAN ENVIRONMENT
}

\author{
O. D. Ojuh ${ }^{1}$ and J. Isabona ${ }^{2, *}$

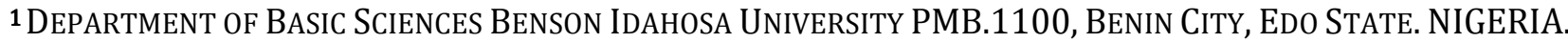 \\ 2 Department of Physics, Federal University Lokoja, PMB. 1154, Lokoja, Kogi STATE, NigeriA. \\ Email addresses.1 dojuh@bui.edu.ng, ${ }^{2}$ jisabona@biu.edu.ng
}

\begin{abstract}
For some time now, members of the public have been concerned about the possible feared health impacts and safety of new $R F$ technologies, including radar, radio and television broadcasting facilities, microwave ovens, pointto-point microwave radio, and satellite communications systems. The most recent concern is the safety of mobile phones and their base stations (BSS). In Nigerian some people believed that exposure to radiation from BSs for long period could cause different diseases like cancer, destroys reproductive organs, congenital anomalies, epilepsy and persistent headache and some of the BSs were installed near the home of residence. Owing to the growing concern, this study was conducted to evaluate the radio frequency radiation levels near several mobile phone BSs in GRA, Benin City, Nigeria. Measurements in terms of power density were made to check the exposure level at public locations. The data (power density) were collected from three (3) major GSMoperators BSs in Nigeria; all the BSs were located in GRA, Benin City, Nigeria. For each of these BSs the measurements were taken at $5 \mathrm{~m}$ intervals to $100 \mathrm{~m}$ from the BSs. From the results, the maximum of power density obtained for GLo, MTN and Airtel are $1.62 \mathrm{~mW} / \mathrm{m}^{2}, 3.04 \mathrm{~mW} / \mathrm{m}^{2}$ and $1.52 \mathrm{~mW} / \mathrm{m}^{2}$ respectively. These values are quite small compared to international standard limits like those adopted by the International Commission on Non-ionizing Radiation Protection (ICNIRP) which is $9 \mathrm{~mW} / \mathrm{m}^{2}$ for the public and $22.5 \mathrm{~mW} / \mathrm{m}^{2}$ for those professionals involved in telecommunication industry.
\end{abstract}

Keywords: Radio Frequency Electromagnetic Radiation, Base Station Antenna, Power density, international Commission on non-ionizing radiation protection.

\section{INTRODUCTION}

The growth of mobile phone communications during the past 15 years has been tremendous and this has led to the installation of more base station antennas in Benin City, Nigeria. This is being done by the network phone operators to support the radio link performance quality of the individual and commercial mobile phone subscribers across the city. According to the Nigerian Communications Commission (NCC), the number of deployed base stations (BSs) or cell sites by the four operators (i.e. Airtel, Etisalat, Globacom, and MTN) grew from zero in2001 to about 44,000 in May 2014. As of May 2014, the GSM operators collectively have a subscriber base of approximately 178 million lines out of which131 million lines were active as. This astronomical growth of GSM deployment suggests a proportionate increase in the amount of radio frequency radiation emitted into the country's air space, a trend that deserves regular monitoring through appropriate measurements of the RF power given out by the base stations [1].

At communication frequency, human body behaves as a dielectric and the EM radiation generated by mobile phone base station are able to penetrate through semisolid substances like living tissues and meat etc. The EM radiation is called the fourth pollution source besides air, water and noise by the environmentalists [2]. Although exposure from base station antennas is far less than that from handheld devices; the public appears to be more concerned about the safety of base stations. For this reason the World Health Organization (WHO) has recommended to undertake research studies on this subject [3].

In Benin City, Nigeria, there is a lack of information about electromagnetic field (EMF) radiation from base 
station antennas and their effects on human health. This study is carried to fill the gap.

In addition, measurements of EMF radiation from base station antennas of the various mobile network operators will be compared with the recommended EMF levels from the International Commission on Non-Ionizing Radiation Protection and other organization.

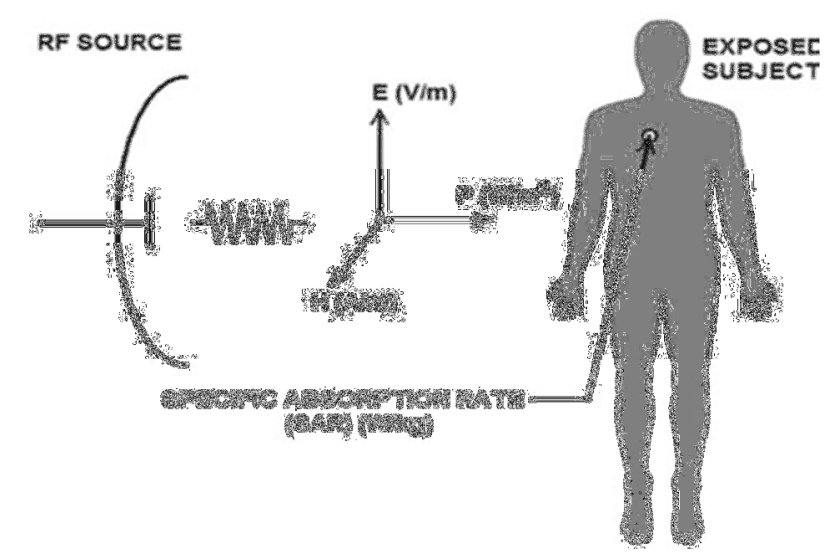

Figure 1: Physical parameters of human exposure to RF energy (Source: [4])

\section{PHYSICS OF ELECTROMAGNETIC RADIATION}

Electromagnetic radiation from mobile phones base stations is generally produced in the form of Radio frequency (RF) Electromagnetic Fields (EMFs) in space. It consists of electric and magnetic field components which are moving waves along perpendicular directions to each other. These are periodic, and the wave propagation direction is in the third axis which is perpendicular to both of them. The interactions of electric and magnetic field components of EMF with each other and with the matter are examined by a set of equation called Maxwell's equations [5]. Mathematically, Maxwell derived a differential and integral wave form of the electric and magnetic equations in free space using four field quantities namely the Electric field intensity (E), the Electric flux density (D), Magnetic flux density (B), and Magnetic field intensity $(\mathrm{H})$ as shown in table 1.

According to these equations, a time varying electric field generates a time varying magnetic field or vice versa. Both electric and magnetic field component oscillate in phase perpendicular to each other as shown in Figure 2. Over a significant propagated distance, EMFs may be categorized into two regions namely the near-field and far-field. The near-field can be further divided into two regions namely the reactive near-field and the radiating near-field. While specific field characteristics of an EMF may be quantified accurately by calculation in the far-field, in practice near-field calculations can carry large uncertainties given that in this region plane wave characteristics have not been established and the relationship therefore between the field quantities can be highly non-linear.

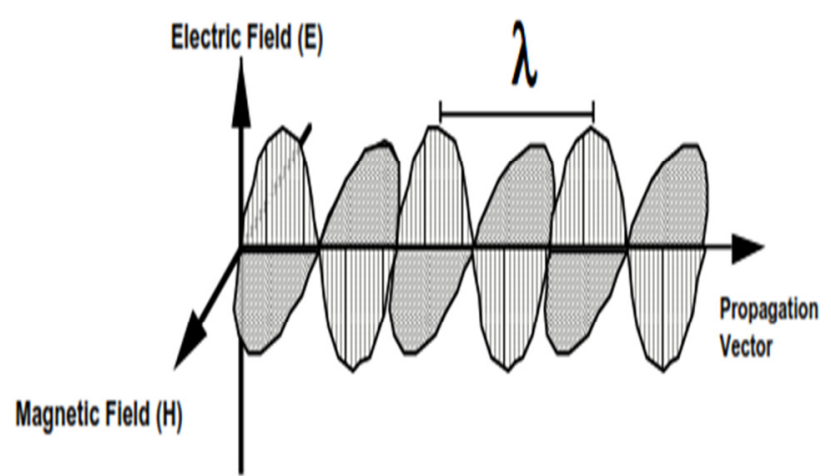

Figure2: Electric and Magnetic fields relationship as described for EMF propagation

Table 1: Maxwell's EMF Equations in Differential and Integral forms

Differential form Integral form

$$
\begin{array}{cc}
\Delta X H=J+\frac{\partial D}{\partial t} & \oint H \cdot d l=I+\int \frac{\partial B}{\partial t} \cdot d s \\
\Delta X E=-\frac{\partial B}{\partial t} & \oint E . d l=-\frac{d \Phi}{d t} \\
\Delta . D=\rho & \oint D \cdot d s=Q \\
\Delta . B=0 & \oint B \cdot d s=0
\end{array}
$$

The near-field and far-field are regions of the electromagnetic field around the antenna. Nonradiative 'near-field' behaviors of electromagnetic fields dominate close to the antenna or scattering object, while electromagnetic radiation 'far-field' behaviours dominate at greater distances. Near-field strength decreases with distance, whereas far-field strength decreases with the square of the distance.

While the far field is the region in which the field acts as "normal" electromagnetic radiation, where it is dominated by electric-dipole type electric or magnetic fields, the near field is governed by multiple type fields, which can be considered as collections of dipoles with a fixed phase relationship. The boundary between the two regions is only vaguely defined, and it depends on the dominant wavelength $(\lambda)$ emitted by the source.

In the far-field region of an antenna, radiation decreases as the square of distance, and absorption of the radiation does not feed back to the transmitter. However, in the near-field region, absorption of radiation does affect the load on the transmitter. In 
the far-field region, each part of the EMF (i.e., electric and magnetic) is produced by a change in the other part and the ratio of electric and magnetic field intensities is simply the wave impedance.

In general, the purpose of antennas is to communicate wirelessly for long distances using far-fields, and this is their main region of operation.

Also known as the radiation-zone field, the far-field carries a relatively uniform wave pattern. The radiation zone is important because far-fields in general fall off in amplitude by $1 / d$. This means that the total energy per unit area at a distance $d$ is proportional to $1 / d^{2}$. The area of the sphere is proportional to $d^{2}$, so the total energy passing through the sphere is constant. In the far, the free space impedance Zo is given by [6],

$$
Z o=\left|\frac{E}{H}\right|=\sqrt{\frac{\mu_{o}}{\varepsilon_{o}}}=377 \Omega
$$

The power density $P_{d}$ can be determined from either the electric or the magnetic field strength by,

$$
\begin{aligned}
& P_{d}=E \times H \\
& \left|P_{d}\right|=\frac{|E|^{2}}{377}=|H|^{2}
\end{aligned}
$$

Power densities can also be calculated from an antenna provided enough information is given. The gain of an antenna $G$ is related to its effective aperture $A$ by,

$$
G=\frac{4 \pi A}{\lambda^{2}}
$$

The far field power density $P_{d}$ at a distance $\mathrm{d}$ can then be calculated using Friis free space formula,

$$
P_{d}=\frac{P_{o} G}{4 \pi d^{2}}=\frac{A P_{o}}{\lambda^{2} d^{2}}
$$

Where $P_{d}$ is in units of $\mathrm{W} / \mathrm{m}^{2}, P_{o}$ is the power to the antenna in Watts, A is the effective aperture of the antenna, and $d$ is the distance from the antenna in metres.

\section{REVIEW OF RELATED LITERATURE}

Previous scientific studies ( e.g. [1-2], [7-20], have applied a number of methods to investigate the possible health effects owing to human exposure to EMF radiations from mobile phone base stations. A 2003 survey study carried out by Santini [9] in France found a variety of self-reported symptoms such as fatigue, headache, sleep disruption and loss of memory for people who reported that they were living within $100 \mathrm{~m}$ of base stations in urban areas or within $300 \mathrm{~m}$ of GSM cell towers in rural areas.
In [11], characterization of the RF power density and its impact on the inhabitants was carried out in Alakahia and Choba communities, Nigeria using a broad band RF meter. In the paper, maximum power densities were obtained close to the foot of the base stations. In [12], the health impact of radio frequency exposure to the general public in Aba, a city in south east Nigeria were assessed, using a broad band meter. This study was a preliminary study where measurements of RF radiation exposure level from mobile telephone base station antennas were carried the broad band meter. In [13], an assessment of RF power density distribution around GSM and broadcast antenna masts was carried out in Lagos City, Nigeria. The results showed the measured power density values were not likely capable of inducing significant hazardous health effects among the people that are least $6 \mathrm{~m}$ away from the antenna.

In a similar study by Aminu et al [14], measurement and evaluation of electromagnetic radiation $(\mathrm{w} / \mathrm{m}$ )radiated from selected Base Transceiver Stations (BTS) of four major operators namely Airtel, MTN, Etisalat and Glo was carried out in Kaduna state. The measurements were made using handheld Spectrum Analyzer. Maximum radiation values were measured from (BTS) of the selected sites in Kaduna and the results were compared with the standard provided by the International Commission on Non Ionizing Radiation Protection. The paper draws the conclusion that the BTS were safe for use.

In a recent study by Akinyemi et al, [15], power density measurements were made within $100 \mathrm{~m}$ of base transceiver stations. This was done to ascertain the effects of the base transceiver stations on humans in Ikeja Area of Lagos State. The highest value of power density measured was $0.28 \mathrm{w} / \mathrm{m}^{2}$, which far exceeds the ICNIRP exposure limit $(280 \%$ of ICNIRP limit).

\section{MATERIALS AND METHOD}

The materials used in this research are GPS, measuring tape, Extech EMF meter and BS. The Extech meter (Model: EMF 827) is a broadband device for monitoring high frequency radiation in range of 50 $\mathrm{MHz}$ to $3.6 \mathrm{GHz}$. It is used in three axis (isotropic) measurement mode and five digits LCD display offers $\mathrm{mV} / \mathrm{m}, \mathrm{V} / \mathrm{m}, \mu \mathrm{A} / \mathrm{m}, \mathrm{mA} / \mathrm{m}, \mathrm{A} / \mathrm{m}, \mu \mathrm{W} / \mathrm{m} 2, \mathrm{~mW} / \mathrm{m}$ and $\mu \mathrm{W} / \mathrm{cm}$. Using the Extech EMF meter, a fiber measuring tape and global positioning system (GPS), power density measurements were carried out up to $100 \mathrm{~m}$ from each base station antenna at intervals of 5 meters.

Vol. 34 No. 4, October 2015 
Generally, there are different basic external and internal physical parameters or metrics as well as the methods used for the assessment of exposure to radiofrequency EMF. These metric are divided into four categories: (i) incident field metrics (such as electric field, magnetic field and power density), (ii) exposure ratios (which are a measure for the proportion of the exposure of a single wireless communication technology into the total exposure), (iii) absorption metrics (specific absorption rate), and (iv) dose metrics (this metric takes the time into account by multiplying the absorption or incident field metric with time). Presented in figure 1 are some of the basic metrics. In this paper, the focus is on power density. It is the radiant power incident perpendicular to a surface, divided by the area of the surface and is expressed in watts per square metre $\left(\mathrm{W} / \mathrm{m}^{2}\right)$. For the case of plane waves as in figure 2, the power density, the effective electric field strength $E(V / m)$ and the effective magnetic field $\mathrm{H}(\mathrm{A} / \mathrm{m})$ are related to the free space impedance via equation (1)

The data (power density) were collected from the major three (3) GSM operators' base stations (BSs); all the BSs were located in GRA, Benin City, Nigeria. For each of these BSs the measurements were taken at $5 \mathrm{~m}$ intervals to $100 \mathrm{~m}$ from the BSs using the measuring tape. All the BSs are dual band-three sectored antennas; the antennas have inbuilt features which enable them radiate at $1800 \mathrm{MHz}$. The antennas are sectored 120 and the antennas were installed at different heights ranging from $22 \mathrm{~m}$ to $40 \mathrm{~m}$ above the sea level for three network operators (MTN, AIRTEL and GLOBACOM) respectively. The electromagnetic broadband meter was place at approximately $1.5 \mathrm{~m}$ to detect the power density at a given point and the electromagnetic detector was made mobile which permit to taking reading at the desired point while the BSs are fixed.

\section{RESULTS AND DISCUSSION}

Shown in figures 3- 6 are the variations of power density with distance for all the 10 base station sites use for the study. The bar chart plot in figure 7 is given to present the maximum power density attained by all the BSs for comparison. As can be seen in figure 7, the maximum of power density for GLo, MTN and Airtel are $1.62 \mathrm{~mW} / \mathrm{m} 2,3.04 \mathrm{~mW} / \mathrm{m} 2$ and $1.52 \mathrm{~mW} / \mathrm{m} 2$ and these values were recorded for BS 1,5 and 10 respectively. These values are quite small compared to international standard limits like those adopted by the International Commission on Non-ionizing Radiation Protection (ICNIRP) which is $9 \mathrm{~mW} / \mathrm{m}^{2}$ for the public and $22.5 \mathrm{~mW} / \mathrm{m}^{2}$ for those professionals involved in telecommunication industry.

The sudden increase in power density at a distance of $3 \mathrm{~m}$ and $6 \mathrm{~m}$ away in BS 4 and BS 2 could be as a result of additional RF radiations influences from other sources/base stations in the adjacent channels around the reference base stations.

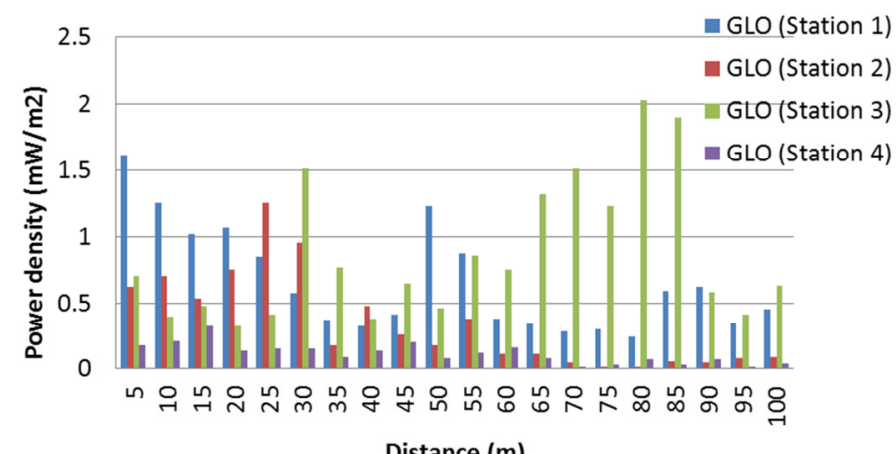

Figure 3: Plot of power density $\left(\mathrm{mW} / \mathrm{m}^{2}\right)$ versus distance (m) for $G L O$

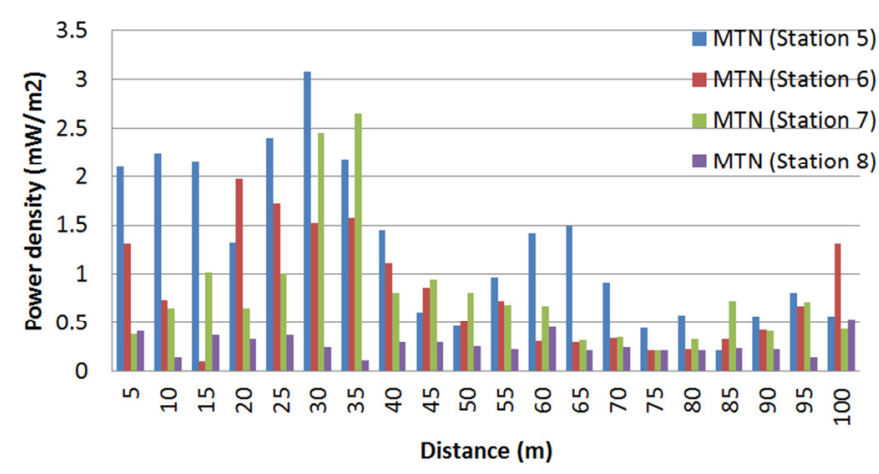

Figure 4: Plot of power density $\left(\mathrm{mW} / \mathrm{m}^{2}\right)$ versus distance (m) for MTN

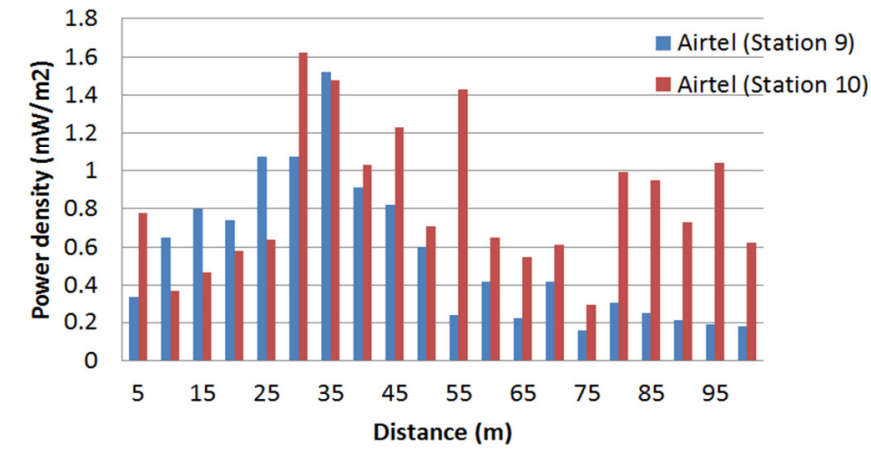

Figure 5: Plot of power density $\left(\mathrm{mW} / \mathrm{m}^{2}\right)$ versus distance (m) for Airtel

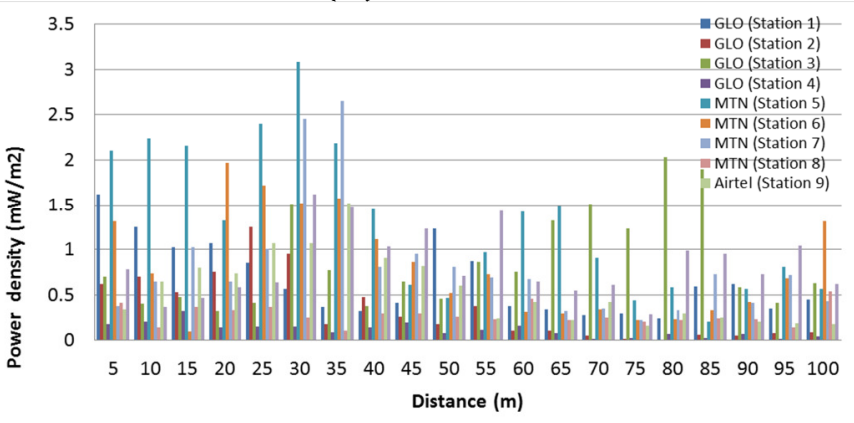

Figure 6: A Plot of power density $\left(\mathrm{mW} / \mathrm{m}^{2}\right)$ versus distance $(m)$ for all the operators

Vol. 34 No. 4, October 2015 


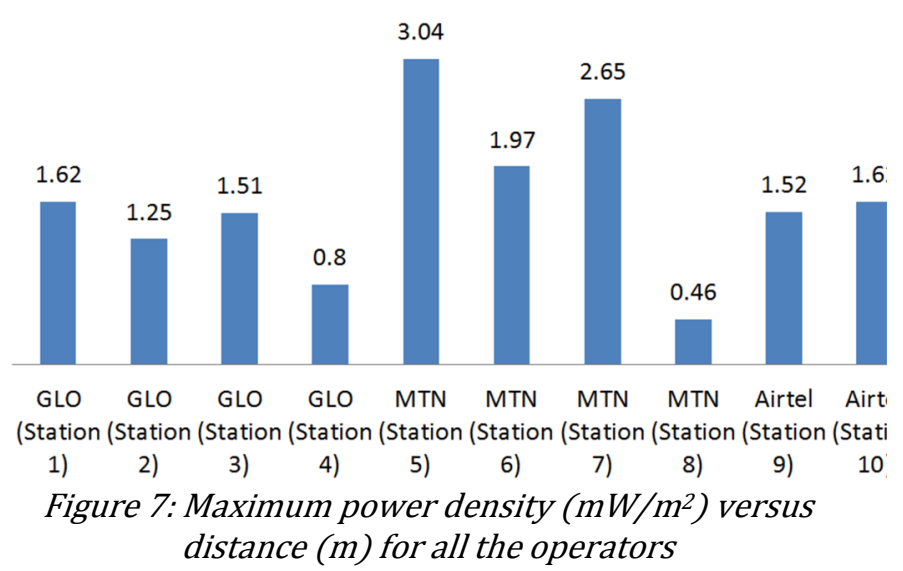

\section{CONCLUSION}

This study was conducted to evaluate the EMF radiation levels around several mobile phone BSs located at public locations, in GRA, Benin City, Nigeria. Practical Measurements in terms of power density were made from three (3) major GSM operators' BSs to check the exposure level in order to determine whether the radiations comply with standards and to assess the risk they pose to the people living near the BSs. For each of these BSs, the measurements were taken at $5 \mathrm{~m}$ intervals to $100 \mathrm{~m}$ from the BSs. From the results, the maximum of power density obtained for GLo, MTN and Airtel stand at $1.62 \mathrm{~mW} / \mathrm{m}^{2}$, $3.04 \mathrm{~mW} / \mathrm{m}^{2}$ and $1.52 \mathrm{~mW} / \mathrm{m}^{2}$ respectively. These values are quite small compared to international standard limits like those adopted by the International Commission on Non-ionizing Radiation Protection (ICNIRP) which is $9 \mathrm{~mW} / \mathrm{m}^{2}$ for the public and $22.5 \mathrm{~mW} / \mathrm{m}^{2}$ for those professionals involved in telecommunication industry.

However, when considering the implications of these results, it is important to appreciate that the sites used for data collection were randomly selected from the study locations and were therefore not necessarily a representative sample of base stations in the country. Considerably more data from a selection of base station sites chosen in a more representative way would be necessary before conclusions could be drawn about the population in general. However, values were assumed to be influenced by some known and unknown factors such as EM radiation from FM and TV antennas, satellite dish, just to mention but a few.

\section{ACKNOWLEDGEMENTS}

We are very grateful to Benson Idahosa University, G.R.A, Benin City, Edo State, Nigeria and Prof. Aluyi, S.A of the Department of Basic Sciences (Microbiology
Unit), Benson Idahosa University for their helpful contributions to the success this work.

\section{REFERENCES}

[1] Ekata, G and Kostanic, I, "Model for Monitoring GSM Base Station Radiation Safety in Nigeria, International, Journal of Engineering Research and Applications, Vol. 4, Issue 10, pp.97-104, 2014.

[2] Sahar Aqeel, A and Jabir S. A, "SAR Simulation in Human Head Exposed to RF Signals and Safety Precautions, Vol. 3, Issue 9, pp 334-340, 2013, Available online @ www.ijcset.net

[3] Kitchen, R., "RF and Microwave Radiation Safety Handbook, "Second Edition, Book, Chapter 3, pp.4785, 2001.

[4] Kyohei, F, "Mobile Antenna Systems Handbook Third Edition, Artech House, INC. 685 Canton Street Norwood, MA 02062, London.

[5] Bayrakçi, E., "Electromagnetic Fields Theory, Birsen Publishing, Istanbul, 59-105, 2000.

[6]Non-Ionization Radiation Safety, http://www.ee.cityu.edu.hk/ assessed $21^{\text {st }}$ March, 2015.

[7] Henderson, S.I, Bangay, M.J, “Survey of RF exposure levels from mobile telephone base stations in Australia", Bioelectromagnetic vol. 27, 73-76, 2006.

[8] Joris, E. and Dirk, B, "A possible effect of electromagnetic radiation from base stations on the number of breeding house sparrows", Research institute for nature International Zurick, pp (181185), ISBN 0-7506-1264-9, 2007.

[9] Santini, R; Santini, P; Danze, JM; LeRuz, P; Seigne, M, "Survey Study of People Living in the Vicinity of Cellular Phone Base Stations". Electromagnetic Biology and Medicine, 2003 http://www.informaworld.com/smpp/content $\sim$ con tent $=$ a713628949

[10] Jokela, K, "Theoretical and measured power density in front of VHF/ UHF broadcasting antennas", Health Physics, Vol. 54, No. 5, 1998.

[11] Enyinna, P.I. and Avwir, G.0 "Characterization of the Radiofrequency Radiation Potential of Alakahia and Choba Communities, Nigeria", Working and Living Environmental protection, vol. 7, pp 25-31, 2010

[12] Asiegbu, A.D. and 0.O. Ogunlaja. "Preliminary Investigation of RF Exposure levels from Mobile Telephone Base Stations in Abia,south east Nigeria", International Journal of Current Research, vol. 11, pp 47-53, 2010.

[13] Ibitoye, Z.A and Ibitoye Aweda, A.M "Ibitoye Z.A and Aweda A.M.2011.Assessment of radiofrequency power density distribution around GSM and broadcast antenna masts in Lagos City, Nigeria Nig," QJ Hospital Med., vol. 21, pp. 35-40, 2011.

[14]Aminu, A, Danladi, A. T, Yahaya, H.A and Zakariyya, H.A "Measurement of Electromagnetic Waves Radiated from Base Transceiver Stations (BTS) for Assessing Exposure Limit in Kaduna State", 
International Journal of Engineering and Science (IJES), vol. 3, Issue 8, pp 28-34, 2014.

[15] Akinyemi, L.A. Shoewu, O. Pinponsu, O.A. Emagbetere, J.O and Edeko, F.O, "Effects of Base Transceiver Station (BTS) on Humans in Ikeja Area of Lagos State", Pacific Journal of Science and Technology, vol. 3, Issue 8, pp 28-34, 2014.

[16] Schirmacher A, Winters S, Fischer S, Goeke J, GallaHJ, Kullnick U, Ringelstein, E.B, Stogbauer F "Electromagnetic fields $(1.8 \mathrm{GHz})$ increase the permeability to sucrose of the BBB in vitro Bioelectromagnetics", pp 338-345, 2011.

[17] Akintonwa, A., Busari, A.A, Awodele, 0 and Olayemi, S.O, "The Hazards of Non-Ionizing Radiation of Telecommunication Mast in an Urban Area of Lagos,
Nigeria", African Journal of Biomedical Research, Vol. 12, No. 1 pp 31-35, 2009.

[18] Sabah, H. and A. Saeid, "Theoretical Estimation of Power Density Levels around Mobile Telephone Base Stations", Journal of Science \& TechnologyVol. (13) No. 2, pp 1-8. 2008.

[19] Anyaka, B. O. and Akuru, B. U., "Electromagnetic Wave Effect on Human Health: Challenges for Developing Countries", IEEE International conference on Cyber-Enabled Distributed Computing and Knowledge Discovery, CEPA, 2012.

[20] Victor, U.J., N. Norbert, S. Silas, “Abraham, A and Patrick, U, "Assessment of Radio Frequency Radiation Exposure Level from Selected Mobile Base Stations (MBS) in Lokoja". Kogi State, Nigeria, Medical Physics, pp. 1-12, 2012. 